\title{
Optical fiber sensor for atmospheric reentry experiments
}

Emile Haddad, Kamel Tagziria, Hongxin Chen, Florian Klinberg, Ali Guelhan, et al.

Emile Haddad, Kamel Tagziria, Hongxin Chen, Florian Klinberg, Ali Guelhan, Brahim Aissa, David Barba, lain McKenzie, "Optical fiber sensor for atmospheric reentry experiments," Proc. SPIE 11852, International Conference on Space Optics - ICSO 2020, 118523G (11 June 2021); doi: $10.1117 / 12.2599547$

SPIE Event: International Conference on Space Optics - ICSO 2021, 2021, Online Only 


\section{International Conference on Space Optics-ICSO 2020}

Virtual Conference

30 March-2 April 2021

Edited by Bruno Cugny, Zoran Sodnik, and Nikos Karafolas
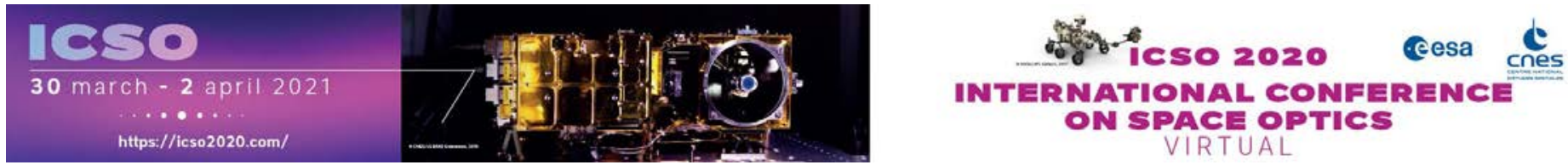

\section{Optical fiber sensor for atmospheric reentry experiments}

\section{Cesa isso procedings denes}




\title{
Optical Fiber Sensor for Atmospheric Reentry Experiments
}

\author{
Emile Haddad ${ }^{* a}$, Kamel Tagziria ${ }^{a}$,Hongxin Chen ${ }^{a}$, Florian Klinberg ${ }^{b}$, Ali Guelhan ${ }^{b}$, Brahim Aissa $^{c}$, David Barba $^{d}$, \\ Iain McKenzie, \\ aMPB Communications Inc., Pointe Claire, Québec, emile.haddad@mpbc.ca, 514-694-8751, \\ ${ }^{b}$ DLR, Cologne, Germany \\ ${ }^{\mathrm{c}}$ Qatar Environment and Energy Research Institute (QEERI), Hamad Bin Khalifa University, \\ ${ }^{\mathrm{d} I N R S-E M T, \text { Varennes, Canada }}$ \\ ${ }^{\mathrm{e} O p t o e l e c t r o n i c s ~ S e c t i o n, ~ E S T E C, ~ E u r o p e a n ~ S p a c e ~ A g e n c y, ~ N o o r d w i j k, ~ T h e ~ N e t h e r l a n d s ~}$
}

\begin{abstract}
Reliable temperature measurements of hot structures of re-entry vehicles are one of the main challenges associated with atmospheric heating. During re-entry, several minutes at hypersonic velocities results in severe aerothermal loads on some components and leads temperature increase of more than $1000^{\circ} \mathrm{C}$. In contrast to single-point measurements provided by thermocouples, optical fiber sensors allow temperature measurement at multiple positions along the fiber line. Key challenges of this technique include packaging, integration, and extraction of the temperature contribution from a signal that is also influenced by strain effects.

MPBC developed optical fiber sensors for such temperatures with special packaging optimizing between protective capability and fast thermal conductivity. The fiber sensors were initially calibrated with thermocouples using a standard oven, then through a test in the DLR arc-heated wind tunnel $\mathrm{L} 3 \mathrm{~K}$ at $1000^{\circ} \mathrm{C}$.

To monitor accurately the fast heat fluxes in reentry two special ruggedized interrogation modules (Interrogator) were developed with data acquisition at $100 \mathrm{~Hz}$ and $3.5 \mathrm{kHz}$. Each Interrogator has a large memory capacity to save data during 1 hour, and a USB memory stick as back up. The Interrogators were validated for vacuum, thermal cycling, and vibrations, being completely functional during the tests. The vibration tests were performed successfully with the accurate sweeping tunable Fabry-Perot Interferometer functional during the vibrations in the X, Y, and Z-axis. DLR integrated both $100 \mathrm{~Hz}$ and $3.5 \mathrm{kHz}$ into the hypersonic flight experiment ATEK for measuring temperature distribution of the motor case of the second stage motor and hybrid module structure, respectively. The $3.5 \mathrm{kHz}$ Interrogator was integrated into the hybrid module, which was part of the launcher block equipped with a parachute. The $100 \mathrm{~Hz}$ Interrogator was integrated into the rocket second stage and performed the return flight without parachute and allowed testing the impact resistance of the new DLR's data acquisition system and some measurement techniques.

The ATEK flight experiment was successfully launched on the 13th of July 2019 from the launch site Esrange in Kiruna and provided valuable flight data $[1,2,3]$. The second stage and the payload reached an apogee of approx. $240 \mathrm{~km}$ and continued the descent without any thrust and landed about 500 seconds after the take-off at a distance of approx. $67 \mathrm{~km}$ from the launch site. The Health Monitoring System allowed the measurement of aerothermal and mechanical loads on the hybrid payload structure and the motor case, along with the complete flight. Part of the data has been transmitted during the flight to the ground via telemetry at a low sampling rate of several Hertz. In addition, several impactresistant data acquisition units could acquire the data at a high sampling rate up to several Kilohertz and stored it onboard. The complete flight data of all data acquisition units is available. The housing of the $3.5 \mathrm{kHz}$ interrogator and its memory stick box was completely undamaged. All four fiber optic connectors were still attached. MPB will recuperate and evaluate its functionality. The $100 \mathrm{~Hz}$ Interrogator, without protection, impacted the ground with a velocity of about $95 \mathrm{~m} / \mathrm{s}$ and was damaged due to the impact.
\end{abstract}

Keywords: Optical Fiber Sensors, High temperature, Reentry experiment, Fast Optical Fiber Interrogators

*emile.haddad@mpbc.ca; phone 1514 6948751; www.mpbc.ca

\section{INTRODUCTION}

Atmospheric reentry occurs at hypersonic velocity and is accompanied by a severe heat loads for a few minutes on the exposed materials, leading to a temperature increase of more than $1000^{\circ} \mathrm{C}$ at certain locations of the spacecraft. The need for in-flight research comes from the lessons learned from the past flight tests programs such as Mirka, SHEFEX (DLR) and IXV (ESA), and US (X-series, SpaceX, Blue-Origin) as well as Japanese (Hyflex, Ortex); where system expertise was gathered through flight experimentation.

Materials with high aerothermodynamics performance and characteristics are required to safely fly hypersonic aerospace vehicles, during re-entry. Thermal protection system (TPS) materials are used to shield hypersonic aerospace vehicles from the severe flow heating encountered during atmospheric entry [4]. Depending on the mission characteristics two classes of materials have been proposed: high-temperature ceramics and superalloys. 


\section{FIBER SENSORS AND GROUND QUALIFICATION}

The experimental part included the building of the interrogator, the development of the fiber sensor packaging, the validation of the sensors - first in subsonic plasma flow at VKI plasma laboratory in Belgium, then in the arc heated wind tunnel L3K with hypersonic flow field at DLR-Cologne. Furthermore, the measurement system had to pass several ground environmental tests with respect to mechanical loads. After calibration and ground qualification, the system was integrated into the payloads of the DLR's flight experiments ROTEX-T and ATEK, which were carried out in August 2016 and July 2019, respectively.

\subsection{Fiber sensor}

MPB developed optical fiber sensors based on Fiber Bragg Gratings (FBG), for temperatures up to $1000^{\circ} \mathrm{C}$ using goldcoated fibers with special packaging optimizing between protective capability for the passive fiber and fast thermal conductivity on the sensor locations.

The FBGs undergo a decay and regeneration process the first time brought to temperature $>750^{\circ} \mathrm{C}$. The fiber sensors were regenerated at $900^{\circ} \mathrm{C}$ as optimal temperature for regeneration (Figure 1), during a period of a few hours, then we calibrated the regenerated FBG response to temperature with thermocouples using a standard cylindrical ceramic oven. A preliminary test confirmed the stability of the FBG intensity and Central WaveLength (CWL) of the sensors at $1000^{\circ} \mathrm{C}$ for 24 hours.

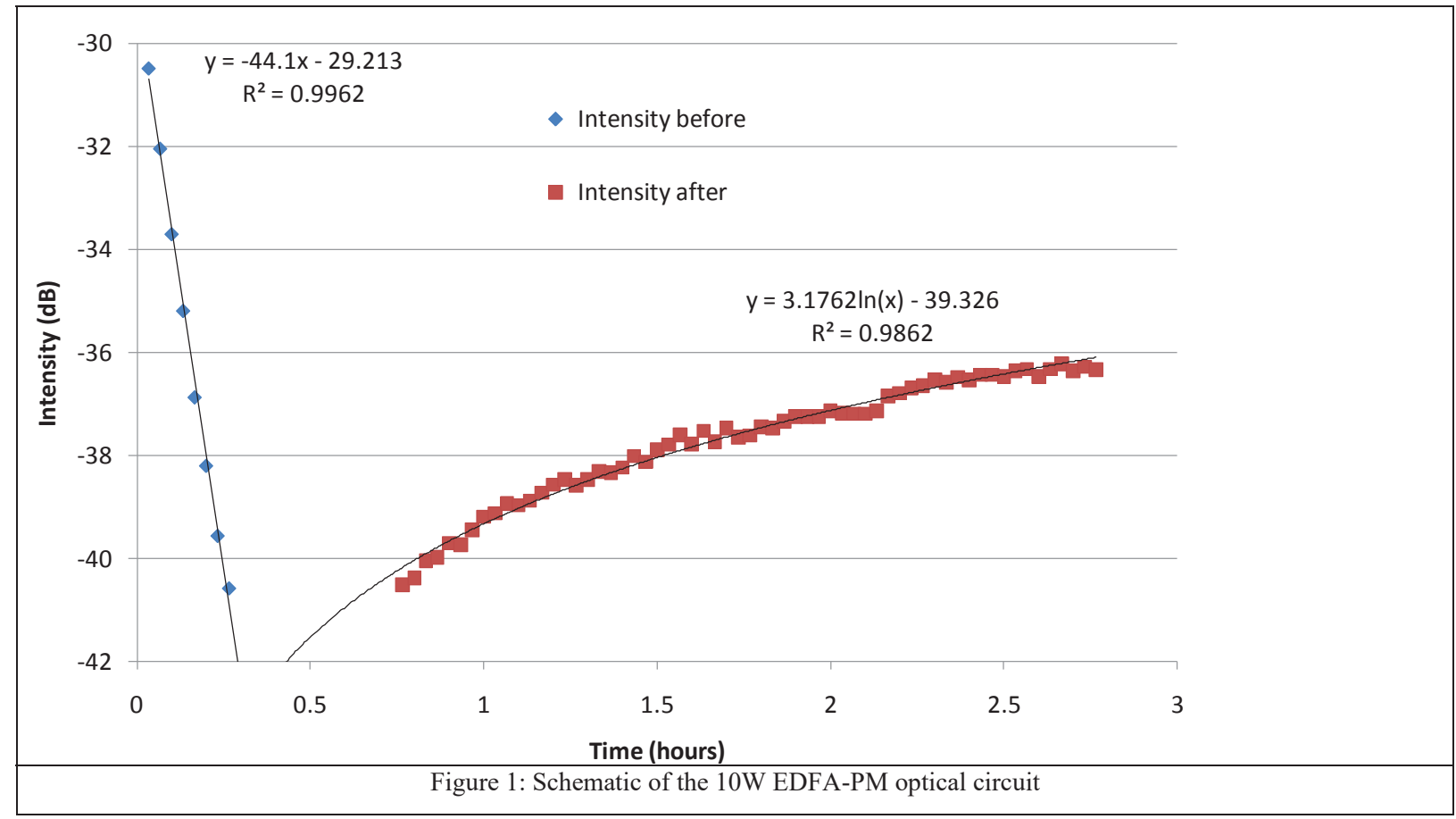

The regenerated FBGs stay up to about $1350^{\circ} \mathrm{C}$, however, the fiber becomes fragile after the gold melts at about $1050^{\circ} \mathrm{C}$. Although the regeneration is completely reproducible, it is not well understood, it is a complex mixture of physical and chemical phenomena, happening in the FBGs. A collaboration with a university team (INRS-EMT) is addressing this issue [5]. Table 1 summarizes the characteristics of FBGs sensors used at MOPB with their corresponding temperature range and test duration

Table 1: Temperature Fiber Sensors prepared

\begin{tabular}{|c|c|c|}
\hline Temperature range $\left({ }^{\circ} \mathrm{C}\right)$; Duration & Fiber coating & Packaging \\
\hline Up to $300^{\circ} \mathrm{C}$; Long duration & Polyimide; FBG Standard & Flexible (Teflon) or metallic \\
\hline Up to $450^{\circ} \mathrm{C} ;<10$ minutes & Polyimide; FBG Standard & Stainless steel very thin; OD about $0.6 \mathrm{~mm}$ \\
\hline Up to $750^{\circ} \mathrm{C}$; Long duration & Gold; FBG Standard & Stainless steel very thin; OD about $0.6 \mathrm{~mm}$ \\
\hline Up to $1000^{\circ} \mathrm{C} ;$ A few minutes & Gold; FBG Regenerated & Stainless steel very thin; OD about $0.6 \mathrm{~mm}$ \\
\hline Up to $1000^{\circ} \mathrm{C} ;$ Long duration & Gold; FBG Regenerated & $\begin{array}{c}\text { Custom made high-temperature alloys; } \\
\text { O.D1.1 mm. Tested for one week- at } 1000^{\circ} \mathrm{C}\end{array}$ \\
\hline Up to $1200^{\circ} \mathrm{C} ; 3-4$ minutes & Gold; FBG Regenerated & Gold coating melts $>1050^{\circ} \mathrm{C}$ \\
\hline
\end{tabular}




\subsection{Calibration and testing in a reentry plasma environment}

A representative fiber sensor package was attached to one metallic (Hastelloy 230) and one ceramic (C/SiC) prototype. These packages were validated at the Von Karman Institute - Belgium (VKI) plasmatron in a harsh environment similar to reentry plasma [6].

The pre-flight validation of the fiber sensors was performed in the arc heated wind tunnel at DLR (Cologne-Germany), simulating the reentry at hypersonic speeds up $3.5 \mathrm{~km} / \mathrm{s}$ and panel structure surface temperatures up to $1000^{\circ} \mathrm{C}$ (Figure 2). The device tested was a $(\mathrm{C} / \mathrm{SiC})$ tile, $150 \mathrm{~mm} \times 250 \mathrm{~mm} \times 3 \mathrm{~mm}$ thick, similar to those installed on SHEFEX series reentry vehicles built by DLR [7,8]. The tile embedded three (3) fiber lines, each of them containing three (3) sensors, in addition to a dozen of thermocouples (Figure 2) that permitted to show the similarity between the transients and plateaus temperatures seen by the Fiber sensors $(100 \mathrm{~Hz}$ acquisition) and those seen by the thermocouples (10 $\mathrm{Hz}$ acquisition).

As shown in Figure 3, the $\mathrm{C} / \mathrm{C}-\mathrm{SiC}$ tile is completely in the hypersonic flow core of the L3K facility. The high illumination of the leading-edge shock allows to visualize it. The model holder is water cooled and can sustain heat flux loads of several MW/m2. Several Type-K thermocouples, which are functional at temperatures up to $1200^{\circ} \mathrm{C}$, were integrated close to the optical fibres to measure the back-surface temperature of the tile with two independent techniques.

Figure 4 shows the surface temperature evolution of the $\mathrm{C} / \mathrm{C}-\mathrm{SiC}$ panel measured with an FPG and thermocouples positioned along a line perpendicular to the flow at the same distance from the leading edge as FBG. The test model is placed outside the flow field during ignition of the arc heater and adaptation of setting parameters until achieving desired steady state flow conditions. After this point (around $60 \mathrm{~s}$ in Figure 4) the model is swept into the flow and achieve the flow middle axis after 1-2 seconds. Combined effects of convective heating from the hot gas, thermal conduction inside material and radiative cooling on the panel surface lead to pronounced temperature gradient in the early phase of the test. Around 140 seconds the radiative equilibrium condition on the model surface is achieved. Besides slight difference in the gradient the FBG sensor measure panel temperature, which is very close to the data measured with all three thermocouples. The temperature decrease around 245 seconds shows the end of hot testing and radiative cooling of the material.

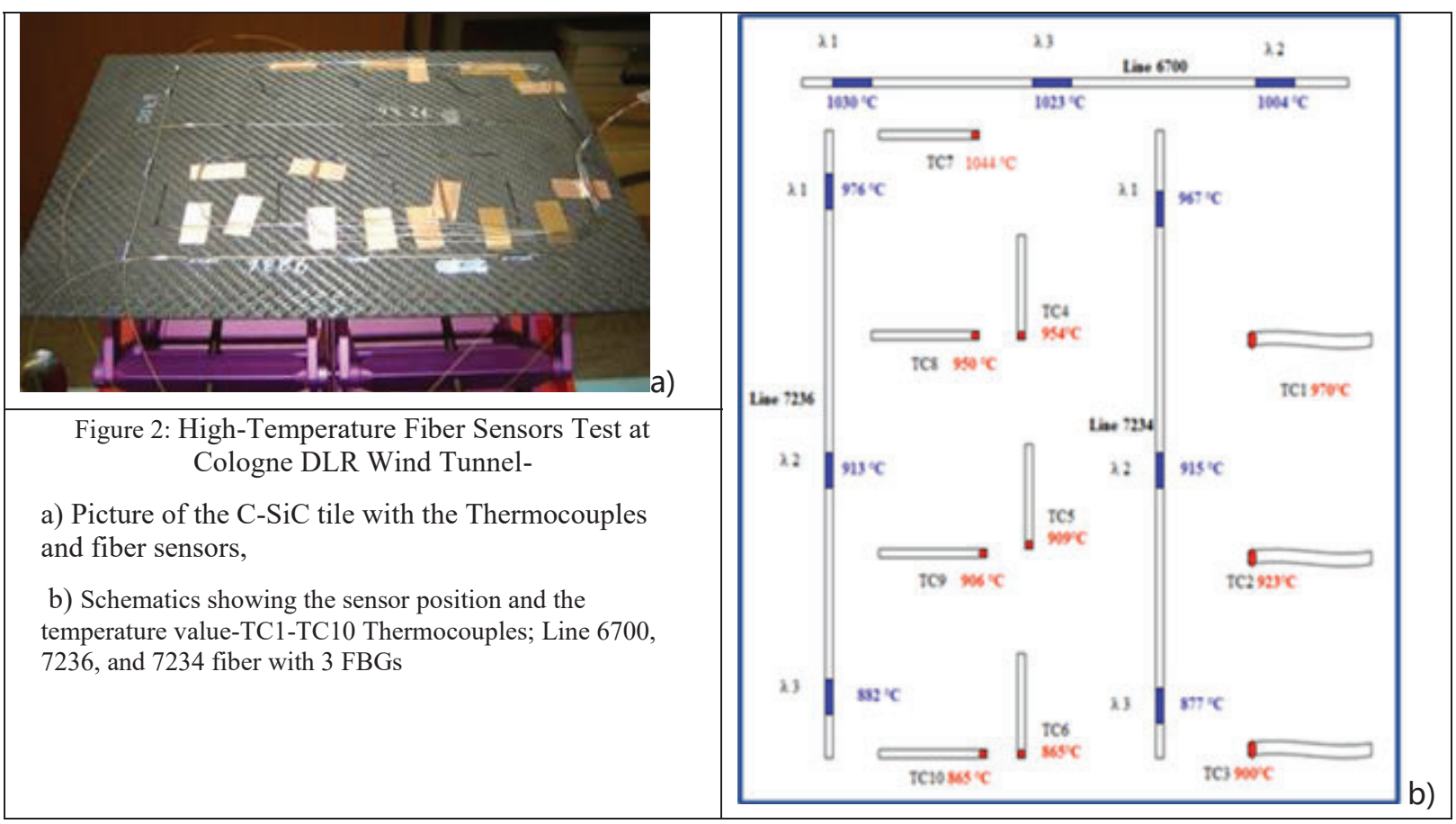




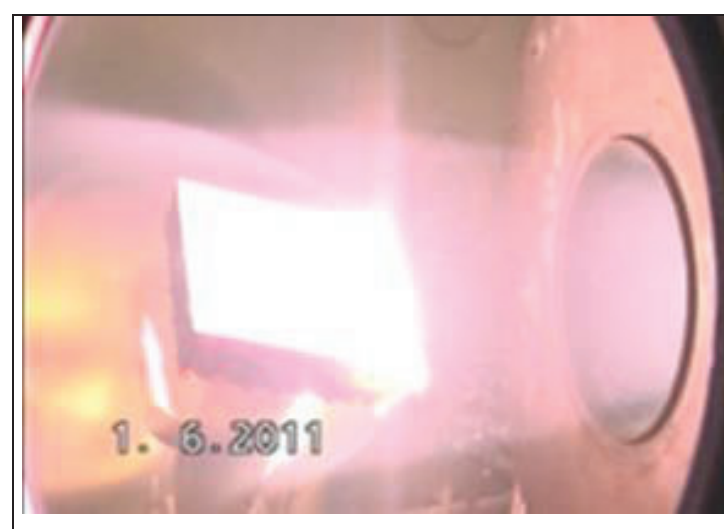

Figure 3. Picture of the wind tunnel test at DLR

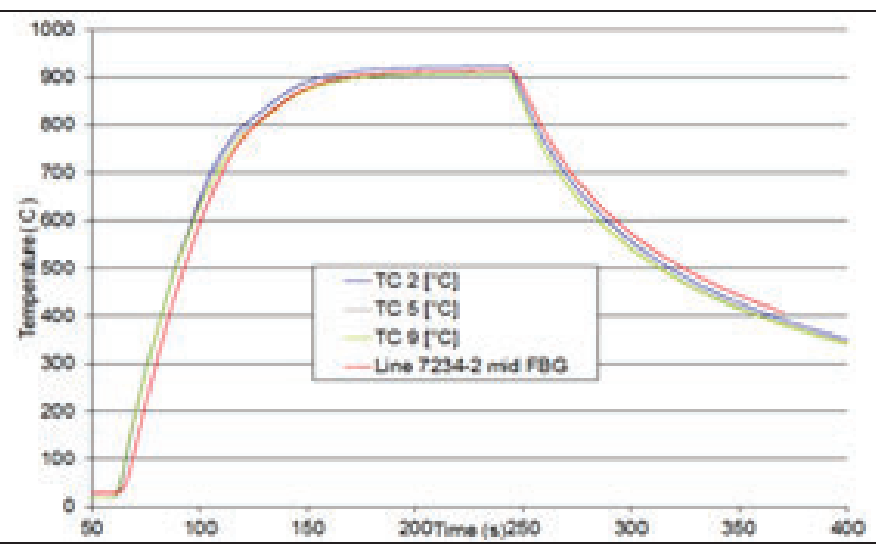

Figure 4. Comparison of the temperature transient and plateau obtained by Thermocouplesand by Fiber Sensors

\subsection{Interrogators}

MPB developed a series of space-qualified fiber sensor systems dedicated to different conditions of measurements (Figure 5). The first generation, uses an Interrogator with a high restriction on mass, size, and power, at $2 \mathrm{~Hz}$ acquisition frequency, suitable for the measurements of housekeeping parameters on a satellite and the slowly changing temperature pressure or strain. Such an Interrogator is flying on Proba-2 ESA's satellite since November 2009 and is still completely functional [9]. The second generation is $100 \mathrm{~Hz}$ acquisition suitable to measure fast transients of temperature and strain during re-entry experiments. The third generation is $3.5 \mathrm{Khz}$ acquisition frequency was developed to monitor launcher health status and vibrations up to $2 \mathrm{kHz}$ resonance frequencies.

To follow the heat fluxes during reentry, we used the second-generation interrogators with data acquisition at $100 \mathrm{~Hz}$. The $100 \mathrm{~Hz}$ interrogator hardware consists of two layers inside the enclosure - the Optical Assembly and the Electronic Assembly. The Optical Assembly fits into the Optical Tray, which is formed into the bottom plate of the enclosure. All optical components, including optical fibers, are mounted and securely plotted on the optical tray (Figure 6).

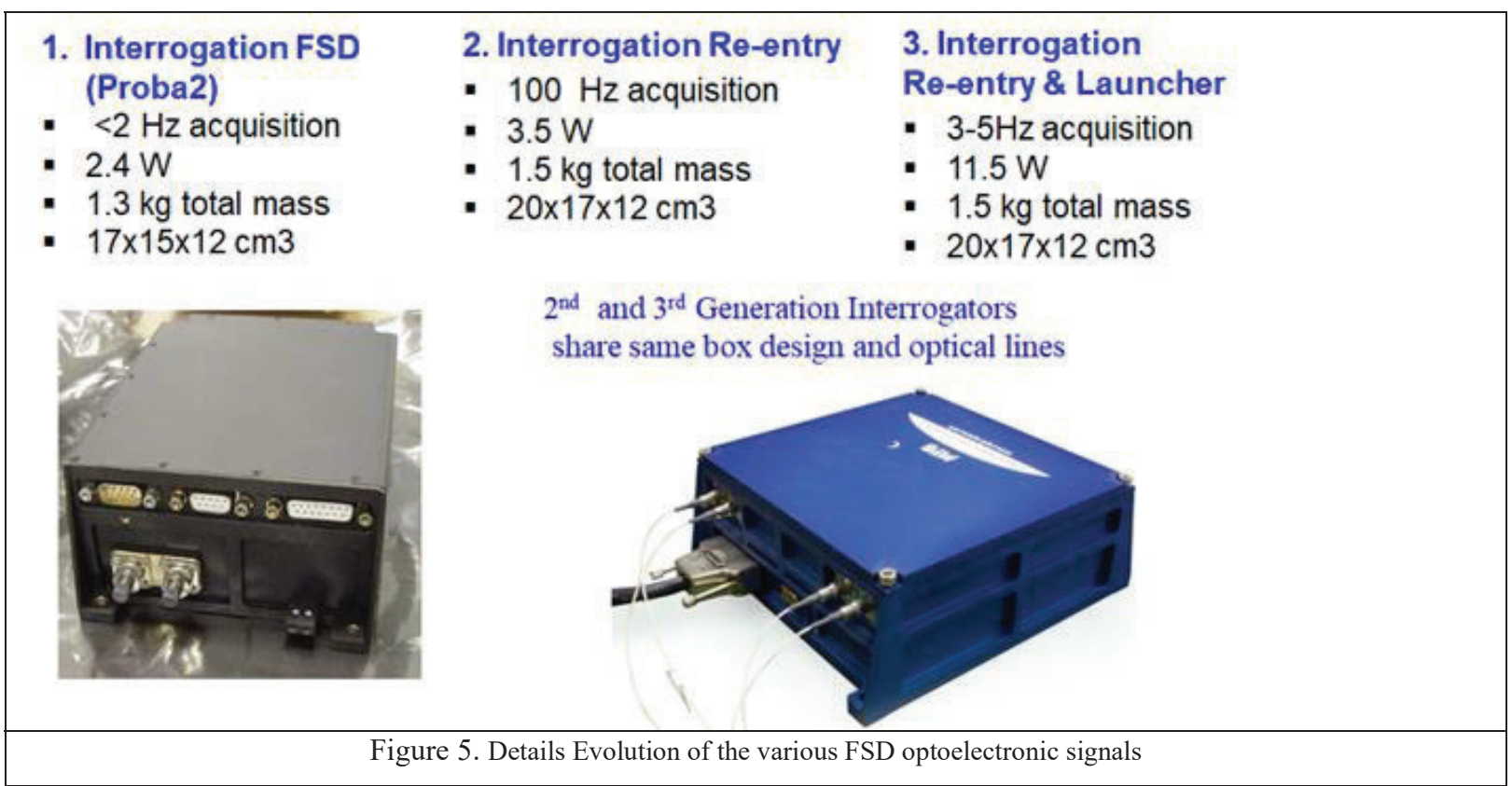




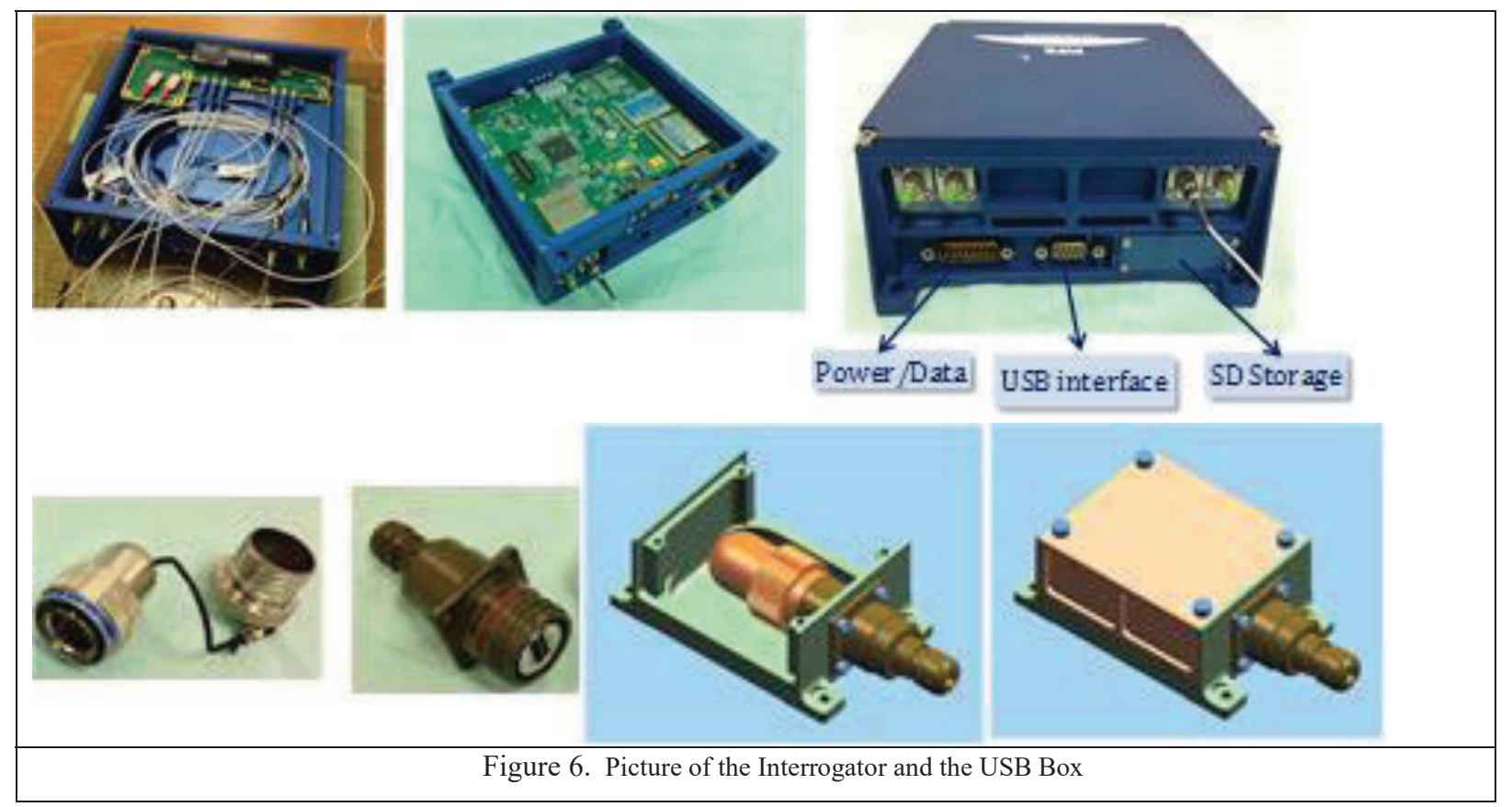

The Optical tray module consists of the Optical Source and the Optical Distribution lines, both of which sit in the Optical Tray. The Optical Source provides a tuned broadband source optical signal from $1525 \mathrm{~nm}$ to $1570 \mathrm{~nm}$. The Optical Source includes a tunable Fabry Perot filter. A tuning voltage from 0 to $20 \mathrm{~V}$ can be applied to the piezo actuator monitoring the mirror of the tunable Fabry Perot filter to sweep and adjust the optical transmission wavelength in the range 1520-1570. The Optical Source has a redundant parallel architecture, effectively providing two independent tunable optical sources - one for fiber optic sensors Line_1 and Line_3 and the other for fiber optic sensors Line_2 and Line 4. The two optical sources are pumped by two $9 \overline{8} 0 \mathrm{~nm}$ laser diode pumps, with power split 50:50 to the two optical source lines. The Optical Distribution lines distribute the generated tuned broadband optical source to the external fiber optic sensors (Line_1 to Line_4).

The Electronic Assembly consists of the Electro-Optics Board and the Computing Board. The Electro-Optics Board provides the required tuning voltage and bias current to all the electro-optics components (such as the $980 \mathrm{~nm}$ pump laser diode and the tunable FP filter). It also provides signal conditioning circuits for the AD590 temperature sensors and photodiodes. The Computing Board takes care of data processing and communications.

The new Interrogator has four lines of six sensors each, in addition to a reference FBG inside the interrogator. To select the optimal packaging design of the fiber sensors, a series of fibers were prepared and tested in different small tubes of less than one mm output diameter. The optimal option was to install only one fiber within a small thin stainless steel tube of $0.35 / 0.45 \mathrm{~mm}$ input/output diameters. This design permitted to follow fast transient with a thin wall and at the same time offering a wall strong enough to prevent the tube buckling.

The software is arranged in two levels. The Functional Level includes the modules that control the physical units. The High level includes the Data Acquisition Module and the Communication Plug-in. In addition to the possibility of a continuous download of the temperature, the data is saved on the Interrogator memory and on a USB protected within a metallic box (Figure 6).

The housekeeping parameters (interrogator temperature, laser diode temperature, and power, Fabry Perot signal) were not kept in the memory in order to leave room for the $100 \mathrm{~Hz}$ data acquisition. However, they were saved on the USB.

\section{REENTRY EXPERIMENTS}

\subsection{ROTEX-T Flight Experiment}

DLR performed ROTEX-T (Rocket Technology Experiment-Transition) on 19 July 2016 from the Esrange Space Center near Kiruna in northern Sweden [10,11]. The main purpose of ROTEX-T was the measurement of aerothermal loads on a double cone payload and second stage motor components (Figure 7). 


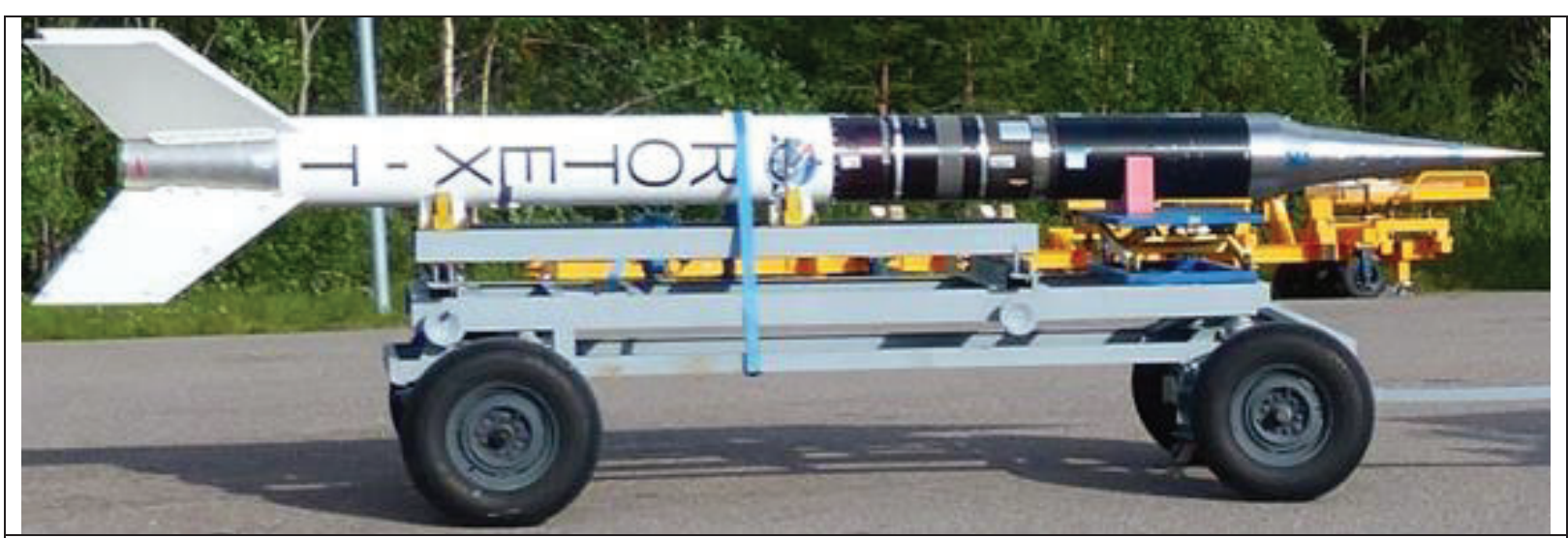

Figure 7. ROTEX-T payload mounted to second stage [10].

The ROTEX-T payload was launched on a two-stage unguided rocket motor configuration. The first stage consisted of the solid propellant motor Terrier Mk12 and for the second stage an Improved Orion (mil. M112 Hawk) motor was used, which is also driven by solid propellant. The Terrier motor has a burn phase of 5 seconds. The Improved Orion motor is a dual thrust burner with a boost phase of 5 seconds and a sustainer phase of approximately 21 seconds. During the complete acceleration phase of approximately 40 seconds a peak acceleration of about $19.4 \mathrm{~g}$ is reached.

Although ROTEX-T was carried out as a low cost flight experiment without inertial measurement unit, reaction control and parachute system, several important achievements were made. The launch, boost, stage separation, Yo-Yo de-spin and payload separation were carried out without any anomaly and a successful payload recovery was achieved. The data acquisition systems worked flawlessly and all flight data were recovered successfully from the on-board memory units after impact. The gathered flight data provided very consistent information which was analyzed in the post flight analysis presented in this paper. The measured sensor data includes heat flux, pressure and temperature measurements for the complete flight trajectory. The vehicle reached maximum Mach numbers of 5.1 and 5.46 during ascent and descent and an apogee of $183 \mathrm{~km}$. Because the vehicle was not equipped with an inertial measurement unit a numerical approach was used to determine angle of attack and sideslip during ascent and re-entry using pressure measurements of four pressure sensors on the cone.

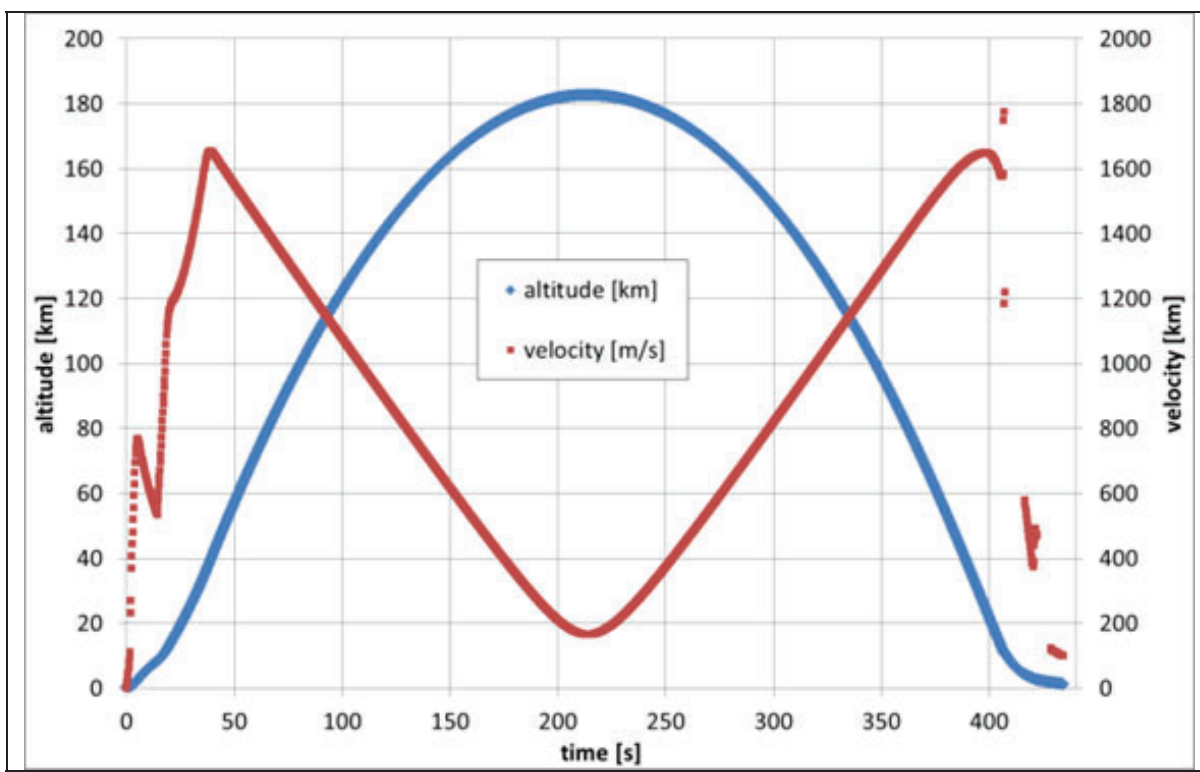

Figure 8. Flight altitude and velocity of ROTEX-T flight experiment [11].

To measure the temperature of the second stage motor case at different locations a fiber optic temperature measurement system (FOS) was integrated into the second experiment service module. Four optic fiber lines with six temperature measurement locations each were attached at the top and bottom location on the motor case [11]. For each location two fibers were routed in parallel for redundancy purposes. Two additional feedthroughs in the motor adapter were used to route the fibers to the electronic box in the service module. The fixation of the optic fibers to the motor housing was done using epoxy adhesive. Additionally, all fiber lines were protected with adhesive Aluminium tape. 
The extension passive fiber between the sensors and the interrogator, broke inside the motor adapter during the rollout to the launch stage. It was not possible to have access to the launch stage for security reasons Figure 9 . The extension passive fiber between the sensors and the interrogator, broke inside the motor adapter during the rollout to the launch stage. It was not possible to have access to the launch stage for security reasons (Figure 9).

During the complete flight, although it could not record any temperature, the interrogator itself worked normally and the telemetry data were received correctly.

The ROTEX-T payload part impacted in the target area with a velocity of about $95 \mathrm{~m} / \mathrm{s}$ (Figure 10). Figure 11 shows the Interrogator and USB after being mounted on the internal ROTEX-T set up, and as recuperated after the reentry experiment and on ground impact The housing of the interrogator and memory stick box was nearly completely undamaged (some of the mounting feet were slightly deformed). As shown in Figure 11 all four connectors survived the impact. Probably all fibres were ruptured due to severe ground impact of the payload.

The internal memory card was removed and was completely functional as tested by DLR. The card was still working normally and the flight data files were downloaded. The reading was correct although no temperatures could be recorded.

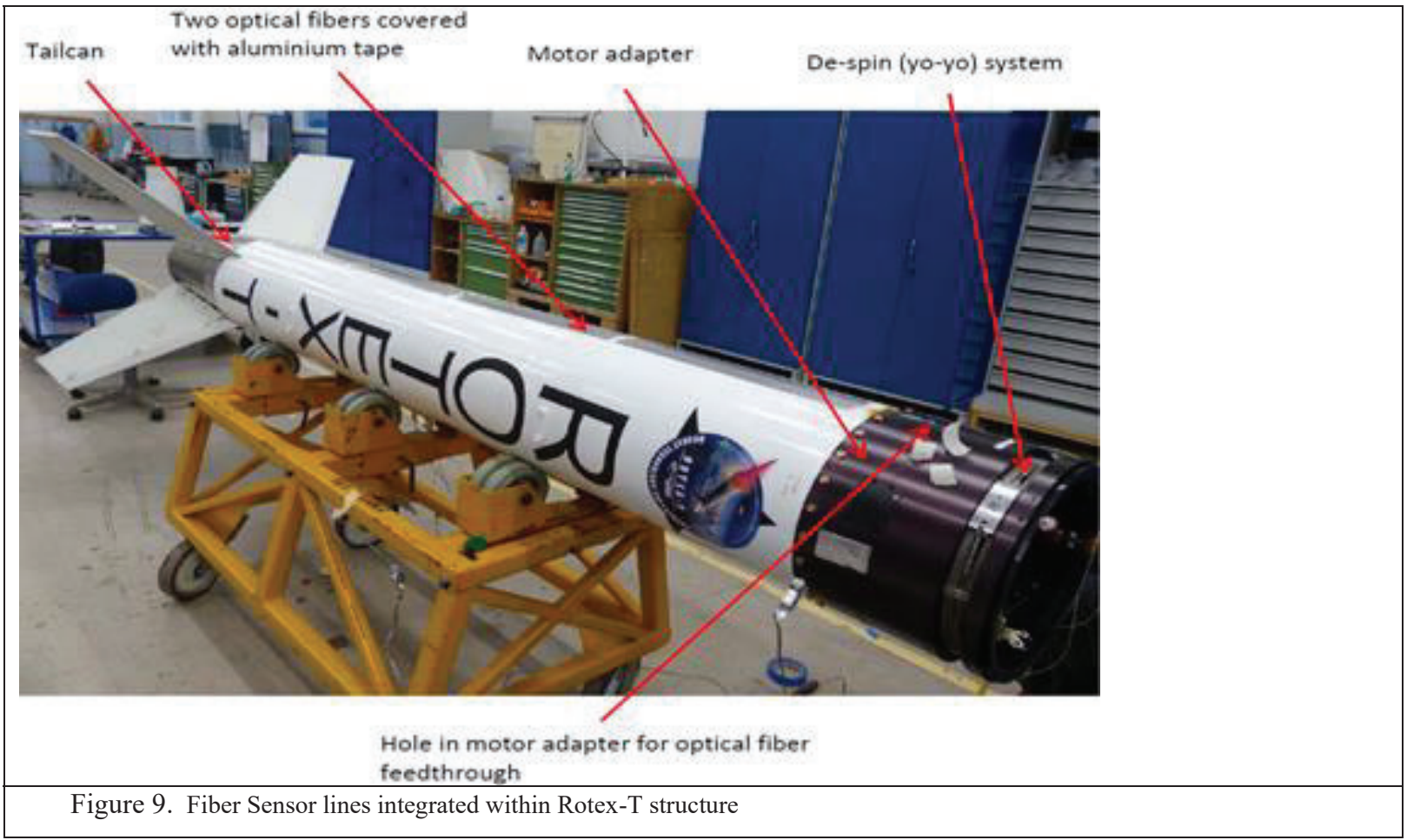

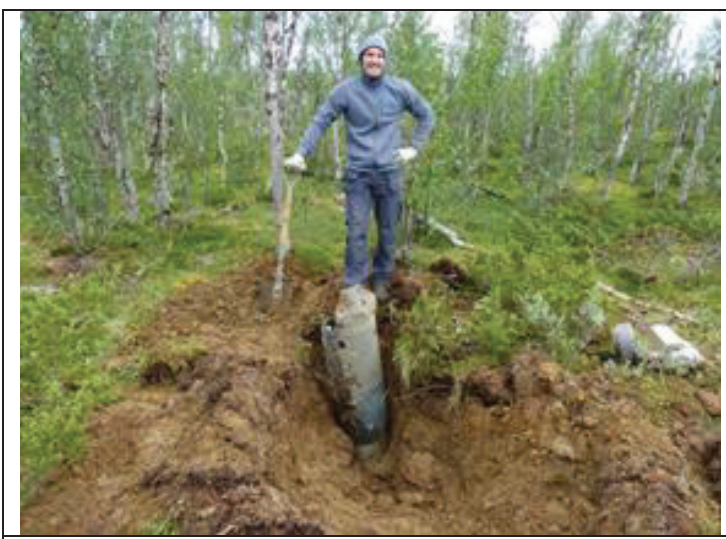

Figure 10. ROTEX-T payload after landing without parachute.

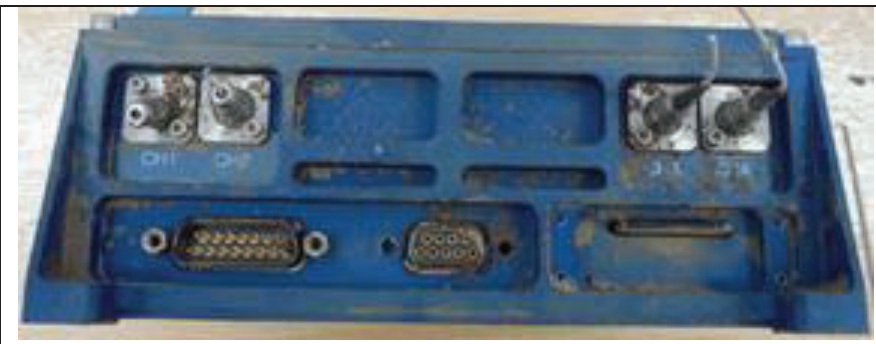

Figure 11. Details of the Interrogator front with the connectors, three of them having their fibers still attached 


\subsection{ATEK Flight Experiment}

Following previous development work concerning in-flight technology demonstration using sounding rockets, DLR performed in July 2019 the ATEK flight experiment. The main objective of the ATEK project (Technologies for Launcher Stages and Components) has been the development and flight qualification of structures, measurement techniques and analysis tools, which are used for thermo-mechanical evaluation of launchers [1,2]. Such flight data, in combination with ground experiment results, are the key element of the validation of physical models, numerical simulation and system analysis tools, which are used to evaluate and to design future space transportation systems. ATEK flight configuration consisted of Health-Monitoring-Systems for critical launcher components and a hybrid payload structure. The first stage motor S31, second stage motor S30, motor adapter, micro-gravity experiments block (MAPHEUS-8), hybrid module and several service / operation modules (Figure 12) [2]. The total length of the flight configuration was approx.12.5 $\mathrm{m}$. The payload section had a diameter of 17 " $(431.8 \mathrm{~mm})$. The second stage and the payload reached an apogee of approx. $240 \mathrm{~km}$ and continued the descent without any thrust and impact landed approx. 500 seconds after the take-off at a distance of approx. $67 \mathrm{~km}$ from the launch site. During ascent the second stage configuration achieved a maximum velocity of approx. $1950 \mathrm{~m} / \mathrm{s}$, which corresponds to a Mach number of 6.1. The complete flight data of all data acquisition units is available.

The Health Monitoring System of ATEK allowed the measurement of aerothermal and mechanical loads on the hybrid payload structure, motor adapter, motor case, tail can and fins along the complete flight. Part of the data has been transmitted during flight to ground via telemetry at a low sampling rate of several Hertz [1]. In addition, several impact-resistant data acquisition units could acquire the data at a high sampling rate of several Kilohertz and stored it onboard. The hybrid payload structure and health monitoring data acquisition units have been recovered after the flight and showed complete functionality. It survived the ground impact of the payload and showed complete functionality of its memory after the flight

On the ATEK flight experiments, we used two interrogators, $100 \mathrm{~Hz}$ and $3.5 \mathrm{kHz}$. About 13 seconds after take-off, the first stage S31 of the launcher was burned-out and separated. The payload, including the $3.5 \mathrm{kHz}$ Interrogator, was decelerated in the late subsonic flight phase using a parachute to avoid a hard impact on the ground after an 800 seconds flight time. The $3.5 \mathrm{kHz}$ housing of the interrogator and memory stick box was nearly completely undamaged. All four fiber optic connectors were still attached. MPB will evaluate its functionality in detail. The $100 \mathrm{~Hz}$ Interrogator was integrated within a cylinder with other payloads. It was not protected and experienced a hard ground impact after a planned uncontrolled descent flight. It was damaged and deformed by the impact.

Figure 13 shows the position of the fiber sensor lines and the two Interrogators, on the ATEK second stage. Figure 14 shows the unprotected $100 \mathrm{~Hz}$ before and broken after re-entry impact. Figure 15 shows the $3.5 \mathrm{kHz}$ after integration, before the test, and once recuperated after the parachute reached the ground it is not affected by the test.

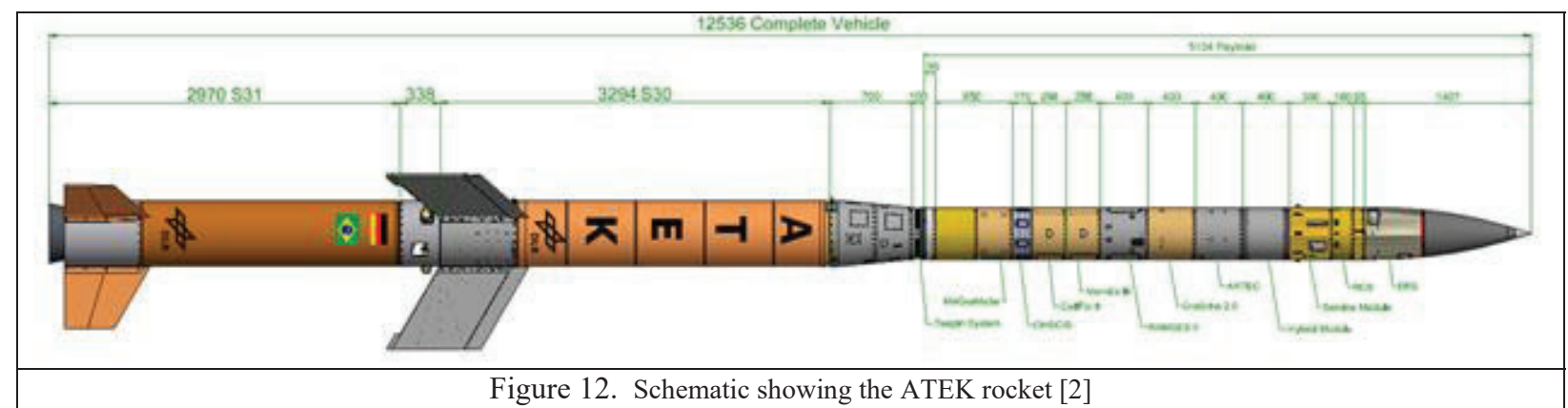

Figure 12. Schematic showing the ATEK rocket [2]

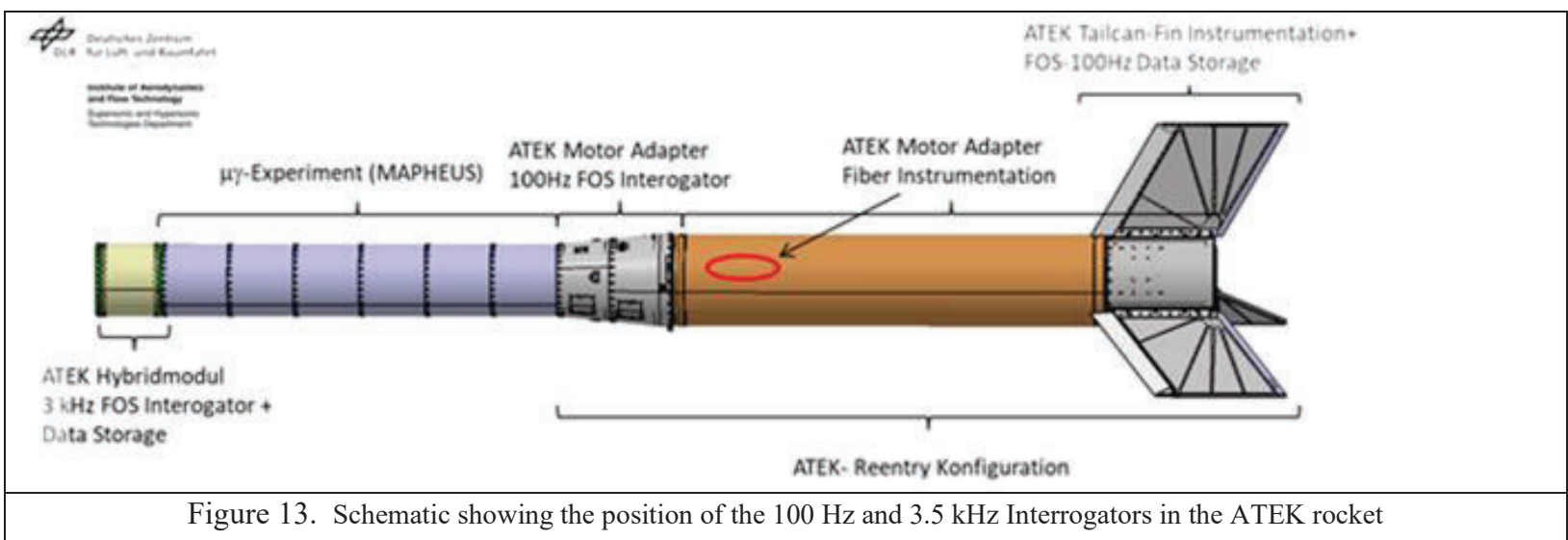




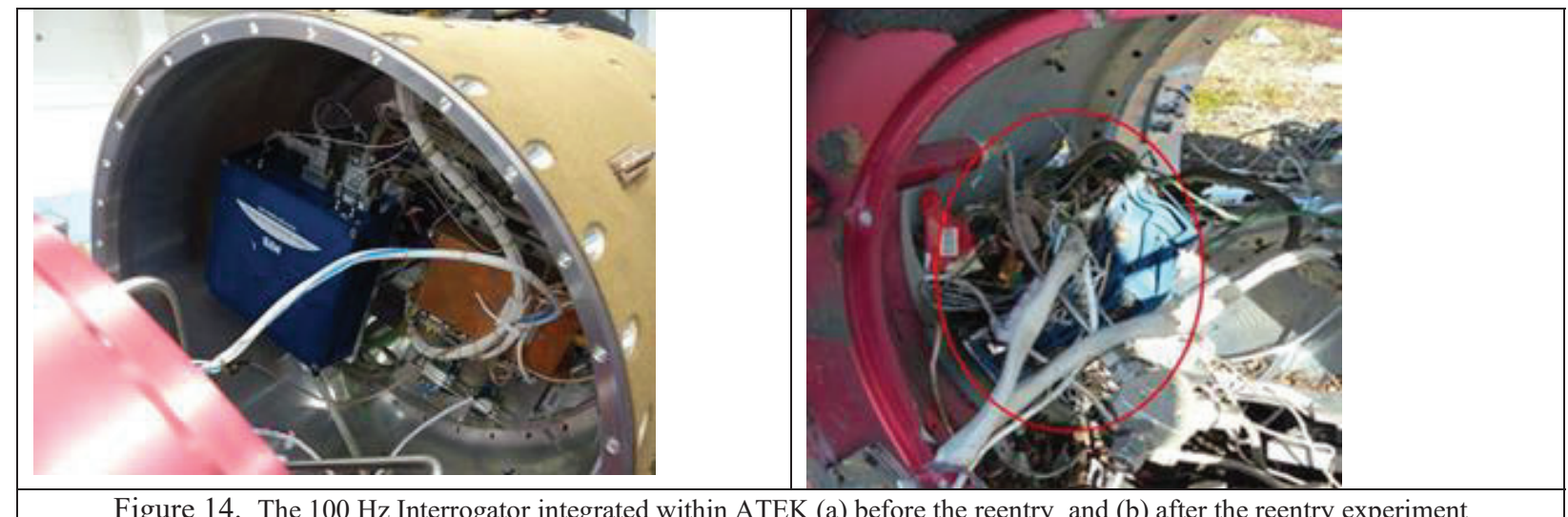

Figure 14. The $100 \mathrm{~Hz}$ Interrogator integrated within ATEK (a) before the reentry and (b) after the reentry experiment
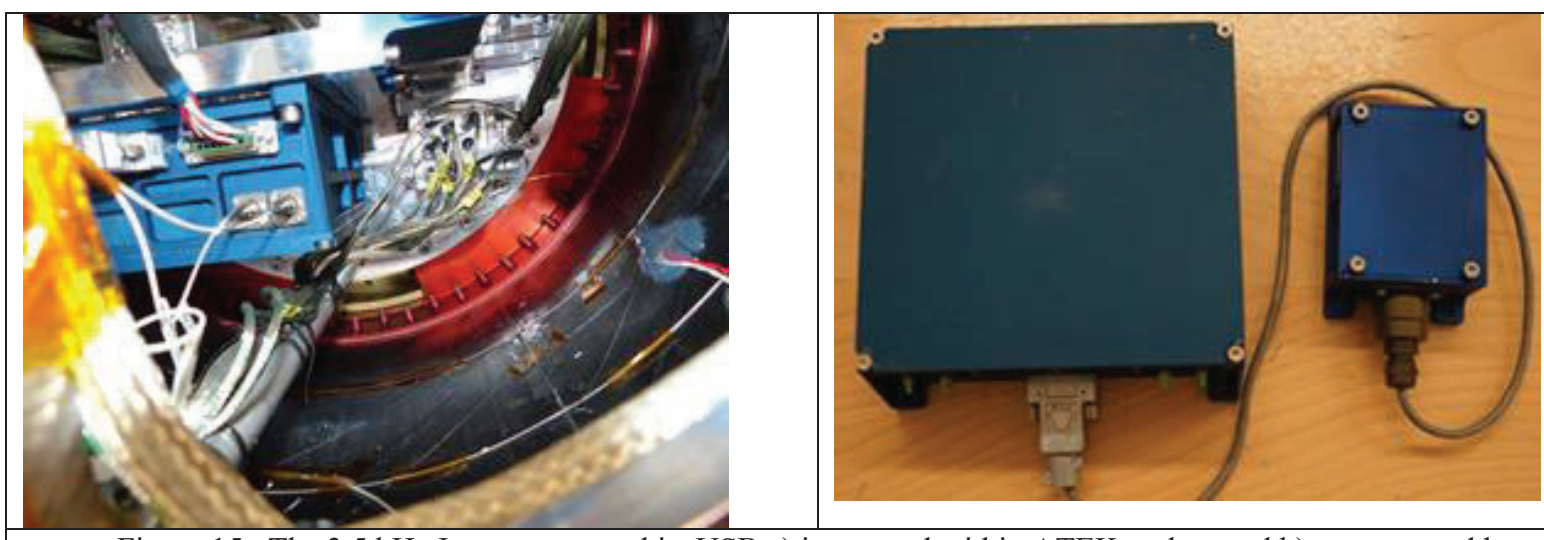

Figure 15. The $3.5 \mathrm{kHz}$ Interrogator and its USB a) integrated within ATEK rocket, and b) recuperated by DLR from the parachute after ATEK-reentry.

Table 2 gives an example of the main housekeeping parameters sent by telemetry: the two thermostats giving the temperature of the bottom surface of the interrogator, ADS590_1, AD590_2; the electrical current LDC_1 and LDC_1 applied on the laser diodes pumping the Erbium-Doped Fiber Amplifier; the corresponding output power LDP_1 and LDP_2; and the internal temperature of the laser diodes LDT_1 and LDT_2.

Table 2: Example of housekeeping parameters sent by telemetry

\begin{tabular}{|c|c|c|c|c|c|c|c|c|c|}
\hline Valid & $\begin{array}{l}\text { Time } \\
\text { (seconds) }\end{array}$ & $\begin{array}{l}\text { AD590_1 } \\
\left({ }^{\circ} \mathrm{C}\right)\end{array}$ & $\begin{array}{l}\text { AD590_2 } \\
\left({ }^{\circ} \mathrm{C}\right)\end{array}$ & $\begin{array}{l}\mathrm{LDC}_{-} 1 \\
(\mathrm{~mA})\end{array}$ & $\begin{array}{l}\mathrm{LDC} 2 \\
(\mathrm{~mA})\end{array}$ & $\begin{array}{l}\mathrm{LDP}_{1} 1 \\
(\mathrm{mV})\end{array}$ & $\begin{array}{l}\text { LDP_2 } \\
(\mathrm{mV})\end{array}$ & $\begin{array}{l}\mathrm{LDT}_{-} 1 \\
\left({ }^{\circ} \mathrm{C}\right)\end{array}$ & $\begin{array}{l}\begin{array}{l}\text { LDT_2 } \\
\left({ }^{\circ} \mathrm{C}\right)\end{array} \\
\end{array}$ \\
\hline 1 & 2368.46 & 17.9 & 18.4 & 222 & 221 & 1205 & 1156 & 23.7 & 24.1 \\
\hline 1 & 2432.72 & 17.9 & 18.2 & 223 & 221 & 1210 & 1153 & 23.7 & 24.1 \\
\hline 1 & 2496.82 & 18.1 & 18 & 222 & 221 & 1210 & 1155 & 23.7 & 24 \\
\hline 1 & 2560.96 & 18.1 & 18.1 & 223 & 220 & 1200 & 1156 & 23.9 & 24 \\
\hline 1 & 2625.12 & 17.8 & 18.4 & 222 & 221 & 1201 & 1160 & 23.9 & 24 \\
\hline 1 & 2689.29 & 18.1 & 18.2 & 221 & 222 & 1206 & 1155 & 23.8 & 24.1 \\
\hline 1 & 2753.62 & 17.8 & 18.2 & 222 & 221 & 1204 & 1155 & 23.9 & 24.2 \\
\hline 1 & 2817.72 & 18.2 & 18.2 & 222 & 223 & 1204 & 1158 & 23.9 & 24.1 \\
\hline 1 & 2881.92 & 17.9 & 18.1 & 223 & 220 & 1206 & 1160 & 24 & 24.1 \\
\hline 1 & 2947.02 & 18.2 & 18.1 & 222 & 221 & 1212 & 1158 & 23.9 & 24.1 \\
\hline 1 & 3010.51 & 17.9 & 18.2 & 223 & 221 & 1215 & 1158 & 23.9 & 24.2 \\
\hline 1 & 3074.67 & 17.8 & 18.4 & 223 & 220 & 1211 & 1155 & 23.8 & 24.3 \\
\hline 1 & 3138.90 & 18.2 & 18.2 & 223 & 221 & 1221 & 1149 & 24 & 24.1 \\
\hline 1 & 3203.02 & 18.2 & 18.4 & 223 & 220 & 1219 & 1158 & 23.8 & 24.1 \\
\hline
\end{tabular}




\begin{tabular}{|r|r|r|r|r|r|r|r|r|r|}
\hline 1 & 3267.18 & 17.8 & 18.2 & 223 & 221 & 1219 & 1159 & 23.9 & 24.2 \\
\hline 1 & 3331.42 & 17.9 & 18.4 & 223 & 290 & 1211 & 1293 & 23.9 & 24.1 \\
\hline 1 & 3396.61 & 17.9 & 18.2 & 221 & 220 & 1215 & 1162 & 24 & 24.4 \\
\hline 1 & 3459.93 & 18.1 & 18.2 & 223 & 221 & 1205 & 1160 & 24 & 24.2 \\
\hline 1 & 3525.15 & 18.1 & 18.2 & 222 & 222 & 1212 & 1161 & 24 & 24.3 \\
\hline 1 & 3588.60 & 18.1 & 18.3 & 223 & 221 & 1230 & 1159 & 23.9 & 24.1 \\
\hline 1 & 3653.71 & 18.1 & 18.3 & 223 & 220 & 1212 & 1159 & 24 & 24.3 \\
\hline 1 & 3717.15 & 18.2 & 18.2 & 223 & 221 & 1215 & 1320 & 23.9 & 23.3 \\
\hline 1 & 3781.35 & 18.2 & 18.2 & 223 & 222 & 1377 & 1160 & 24 & 24.4 \\
\hline 1 & 3845.58 & 18 & 17.8 & 223 & 220 & 1219 & 1159 & 23.2 & 24.2 \\
\hline 1 & 3909.70 & 18.1 & 19 & 223 & 223 & 1216 & 1158 & 297.3 & 24.3 \\
\hline
\end{tabular}

Figure 16 compares the temperature provided by three FBGs on the same line with a close thermocouple [3].

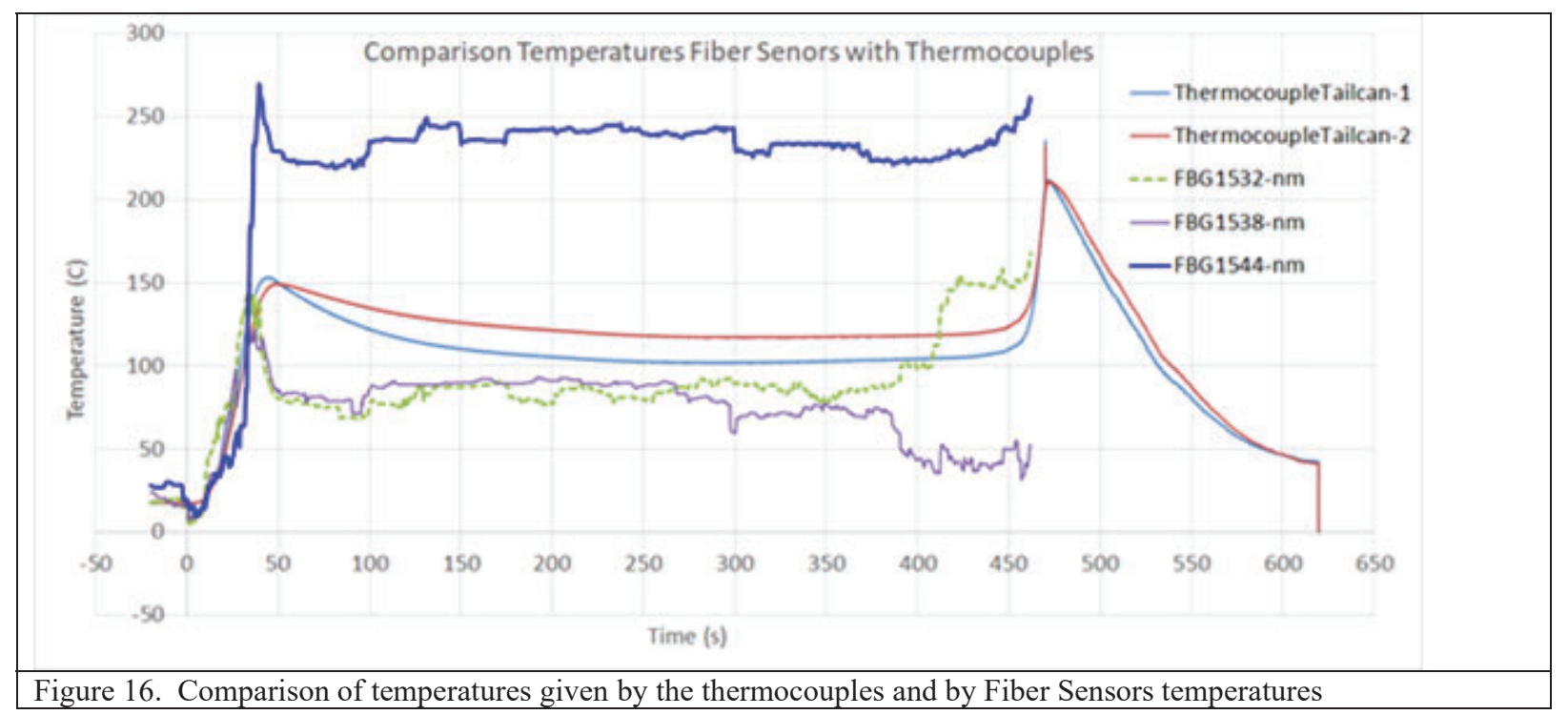

\section{CONCLUSION}

All the sensors and the two Interrogators $(100 \mathrm{~Hz}$ and $3 \mathrm{kHz})$ worked well after the integration and assembly of the successful ATEK flight experiment of DLR.

All housekeeping parameters were transferred correctly during the reentry. The two interrogators responded correctly to housekeeping parameters (laser diode power, thermistors, voltage....) during the whole mission

After transfer to the launch pad some sensors were operational, while the others did not respond. This induces a strong need for deeper analysis and to better protect the FBG sensors by sticking them well to the rocket surface.

The survived FBGs responded correctly to the temperature in agreement with thermocouples used by DLR.

We want to apply this technology to multi-mission spacecrafts and launchers.

\section{REFERENCES}

1. ADTEK page at DLR website https://www.dlr.de/as/en/desktopdefault.aspx/tabid-194/407_read-58040/

2. A. Gülhan, A. Kallenbach, I. Petkov, F. Klingenberg, F. Siebe; Sounding Rocket Flight Experiment ATEK - A

Testbed for Technologies and Components of Launcher Stages, HiSST: 2nd International Conference on High-Speed

Vehicle Science Technology, April 2022, Bruges, Belgium.

3. F. Klingenberg, F. Siebe, R. Kronen, N. Wendel, A. Gülhan; Instrumentation of ATEK Flight Experiment, HiSST:

2nd International Conference on High-Speed Vehicle Science Technology, 20-24 April 2022, Bruges, Belgium 4. Y. Zhu, W. Peng, R. Xu, P. Jiang; "Review on active thermal protection and its heat transfer for airbreathing hypersonic vehicles"; Chinese Journal of Aeronautics, (2018), 31(10): 1929-1953. 
5. M. Celikin, D. Barba, B. Bastola, A..Ruediger, F. Rosei; "Development of regenerated fiber Bragg grating sensors with long-term stability"; Optics Express Vol. 24, (2016) 21897-21909.

6. E. Haddad; R. V. Kruzelecky; K. Tagziria; B. Aissa; Iain McKenzie; A. Guelhan; J.-M. Muylaert; Mert Celinkin; David Barba; "High temperature optical fiber sensor for atmospheric re-entry"; Proc. SPIE 10562, International Conference on Space Optics — ICSO 2016, 105620Z (25 September 2017); doi: 10.1117/12.2296185, Bruno Cugny; Nikos Karafolas; Zoran Sodnik, Editor(s)

7. Weihs, H., Longo, J., and Gülhan, A., "Sharp Edge Flight Experiment SHEFEX," Fourth European Workshop on Thermal Protection Systems and Hot Structures Conference Proceedings, ESA SP-521, Noordwijk, Netherlands, 2002. 8. A. Gülhan, D. Neeb, T. Thiele and F. Siebe; Aerothermal Postflight Analysis of the Sharp Edge Flight Experiment-II. Journal of Spacecraft and Rockets, DOI: 10.2514/1.A33275. ISSN 0022-4650.

9. M. Mena, E. Haddad, F. Hannoteau, R. V. Kruzelecky, K. Tagziria, E. Wallach, F. Ricci, I. McKenzie, N. Karafolas; "Monitoring the Propulsion System of PROBA-2 with Optical Fiber Sensors during 9 Years"; PROBA-2 Symposium: 9 Years of Proba-2 Operations 7-8 February 2019, REDU, Belgium

10. T. Thiele, A. Gülhan, H. Olivier; Instrumentation and Aerothermal Postflight Analysis of the Rocket Technology Flight Experiment ROTEX-T, Journal of Spacecraft and Rockets, Vol. 55, No. 5, September-October 2018.

11. Gülhan, A., Thiele, T., Siebe, F., Klingenberg, F., Kronen, R., "Main Achievements of the Rocket Technology Flight Experiment ROTEX-T", 21st AIAA International Space Planes and Hypersonics Technologies Conference, Xiamen, China, 2017. 